\title{
El parque urbano Nishi-Rokugō o parque de los neumáticos como ejemplo de la cultura de reciclaje en Japón
}

The Nishi-Rokugo urban park or tire park as an example of the recycling culture in Japan O parque urbano ou parque de pneus Nishi-Rokugō como um exemplo da cultura da reciclagem no Japão

\author{
Gilberto Mejía Salazar \\ Universidad Autónoma de Nayarit, México \\ gilberto.mejia@uan.edu.mx \\ https://orcid.org/0000-0002-1879-1299
}

\section{Resumen}

El objetivo principal de esta investigación fue divulgar la importancia de la reutilización de los materiales reciclados de las fábricas locales y vecinales, para lo cual se ha tomado como ejemplo la manera en que los japoneses aprovechan estos recursos para la creación y generación de parques y espacios públicos para el beneficio de la sociedad en general. El referente estudiado fue el parque urbano Nishi-Rokugō o parque de los neumáticos, localizado en Nishi-Rokugō, Ota-ku, en el distrito de Ota, en la metrópoli de Tokio (Japón). Como conclusión se puede indicar que el referido parque constituye un gran referente para el resto de los países, pues se evidencia cómo la cultura de las personas es parte vital para impulsar cambios en las ciudades, donde se necesitan entornos para hacer una pequeña pausa en medio de una cotidianidad tan agitada.

Palabras claves: cultura, educación, Japón, parque urbano, reciclaje, Tokio. 
Revista Iberoamericana

de las Ciencias Sociales y

Humanísticas

ISSN: $2395-7972$

\section{Abstract}

The main objective of this research was to disseminate the importance of reusing recycled materials from local and neighborhood factories, for which the way in which the Japanese take advantage of these resources for the creation and generation of parks and spaces has been taken as an example. Public for the benefit of society in general. The reference studied was the Nishi-Rokugō urban park or tire park, located in Nishi-Rokugō, Ota-ku, in the Ota district, in the metropolis of Tokyo (Japan). As a conclusion, it can be indicated that the aforementioned park constitutes a great reference for the rest of the countries, since it is evident how the culture of the people is a vital part to promote changes in cities, where environments are needed to take a short break in between of such a hectic daily life.

Keywords: Culture, education, Japan, urban park, recycling, Tokyo.

\section{Resumo}

O objetivo principal desta pesquisa foi disseminar a importância do reaproveitamento de materiais reciclados de fábricas locais e de vizinhança, da qual a forma como os japoneses aproveitam esses recursos para a criação e geração de parques e espaços tem sido exemplificada. público em benefício da sociedade em geral. A referência estudada foi o parque urbano Nishi-Rokugō ou parque de pneus, localizado em Nishi-Rokugō, Ota-ku, no distrito de Ota, na metrópole de Tóquio (Japão). Em conclusão, pode-se indicar que o referido parque constitui uma grande referência para o resto dos países, pois fica evidente como a cultura das pessoas é parte vital para promover mudanças nas cidades, onde os ambientes são necessários para curta pausa no meio de uma vida diária tão agitada.

Palavras-chave: cultura, educação, Japão, parque urbano, reciclagem, Tóquio.

Fecha Recepción: Marzo 2020

Fecha Aceptación: Diciembre 2020 


\section{Introducción}

Japón es un país con una fuerte tradición y sensibilidad, y poseedor de una cultura única en el mundo. Actualmente, es conocido por su enorme crecimiento demográfico y económico, (García, 2019), pero también por ser junto a Estados Unidos y Rusia las naciones que utilizan $80 \%$ de los recursos naturales del planeta en las exigencias propias del desarrollo tecnológico y en la producción de bienes utilizables, a pesar de que cuentan con solo la cuarta parte de la población mundial (López, 2009).

Aun así, en Japón se procura aprovechar un alto porcentaje de los residuos sólidos. De hecho, el Ministerio de Medio Ambiente japonés otorga directrices ambientales sobre la gestión de residuos y limpieza pública según la normatividad vigente que se sustenta en la última actualización de la ley de manejo de residuos sólidos y limpieza pública emitida en el año 2010 (Mora, 2018). En consecuencia, Japón ha implementado varias medidas de control no solo en las industrias, sino también en aspectos específicos de la vida cotidiana de las personas, lo que ha generado en ellas comportamientos regulados por la ley para la consecución de los cuidados ambientales de manera eficiente (Mesa y Villa, 2016).

Lógicamente, esta generación y gestión de residuos sólidos requiere del compromiso de la sociedad, gobiernos, academia, medios de comunicación, comunidad, organizaciones e individuos para minimizar los efectos adversos al ambiente y a la salud (Valderrama, Chavarro, Osorio y Peña, 2018). Por ello, desde la década de los años cincuenta del siglo pasado, muchos de los parques urbanos de Japón presentes en las ciudades actuales (como el parque Ueno) fueron construidos en las pocas áreas libres existentes de los jardines de villas, propiedad de las clases nobles de la época anterior a la restauración (Santini, 2015).

\section{El reciclaje en Japón}

El reciclaje se centra en la recolección y separación del objeto que ha concluido su vida útil, de modo que sus partes pueden sufrir transformaciones subsecuentes en productos que puedan volver a utilizarse (Environmental Protection Agency, 2000, citado por Tron, 2011). En palabras de Velázquez (2012), el reciclaje es la transformación de los residuos en nuevos productos después de separarlos y acondicionarlos para que sean usados como materias primas. 


\section{Revista Iberoamericana \\ de las Ciencias Sociales y Humanísticas}

ISSN: $2395-7972$

La importancia de reciclar cobra una dimensión inexistente en otros materiales y ayuda considerablemente a justificar su reciclado. En la década de los 90, la Unión Europea y Japón fueron los líderes en el reciclado de plásticos y otros residuos sólidos (Shelley et al., 1992, citados por Arandes, Bilbao y López, 2004). De hecho, el promedio mundial de reciclaje del PET, en el año 2015, fue de 41 \%, siendo Japón el país con la cifra de reciclaje de PET más alta (78 \%) (Suárez, 2016, citado por Valderrama et al., 2018).

\section{Los parques urbanos en el contexto de la ciudad}

Los espacios públicos en las urbes son variados, pues incluyen alamedas, parques infantiles, parques urbanos, entre otros, los cuales se localizan en puntos neurálgicos de las ciudades. Si bien sus dimensiones son de menor tamaño debido a que son ornamentales, tienen la importancia de ser los pulmones encargados de purificar el aire de las ciudades, además de otorgar a los niños espacios donde puedan divertirse al aire libre (Becker, 2012). Dicho de otro modo, brindan una gran cantidad de beneficios ambientales y sociales, como el equilibrio ecológico y la estabilidad necesaria para las familias de la ciudad y los visitantes (Mejía, 2019). Ellos, por tanto, constituyen un espacio abierto de uso público, donde se establecen relaciones humanas de esparcimiento, recreación, deporte, convivencia comunitaria, educación y cultura dentro de la ciudad (Miranda, 1997).

\section{El parque urbano Nishi-Rokugō o parque de neumáticos}

La muestra más extraordinaria que podemos encontrar de parques de neumáticos es el Nishi-Rokugō o Tyre Park (ubicado en la metrópoli de Tokio), el cual está construido con aproximadamente 3000 viejos neumáticos que forman grandes esculturas de Godzilla, naves espaciales, robots y personajes referentes a la cultura nipona capturan el espíritu creativo que inspiró este parque infantil inusual e innovador (Bellissima Kids, 26 de junio de 2013; Dohrenwend, 2013; Parques de México, 2014).

\section{Objetivo principal}

El objetivo principal de esta investigación fue divulgar la importancia de la reutilización de los materiales reciclados de las fábricas locales y vecinales, para lo cual se ha tomado como ejemplo la manera en que los japoneses aprovechan estos materiales para 


\section{Revista Iberoamericana \\ de las Ciencias Sociales y Humanísticas}

ISSN: $2395-7972$

la creación y generación de parques y espacios públicos para el beneficio de la sociedad en general.

\section{Pregunta de investigación}

La gran demanda y crecimiento de la mancha urbana ha generado la necesidad de crear espacios o áreas de recreación, relajación y esparcimiento a partir del reciclaje. Por ello, se ha planteado la siguiente pregunta de investigación: ¿cuál es el beneficio de llevar una cultura del reciclaje a la vida diaria?

\section{Metodología}

La presente investigación tuvo un enfoque documental, método investigativo basado en la revisión de textos, artículos, bibliografías, videos, películas, entre otros, para iniciar o retomar un tema determinado (Alfonzo, 1994; Restrepo, s. f.). La investigación documental es un procedimiento científico que permite recolectar, sistematizar e interpretar la información recabada (Alfonzo, 1994). Según Espinoza y Rincón (2006), esta metodología se fundamenta en las fases enseñadas en la figura 1.

Figura 1. Fases de la investigación documental

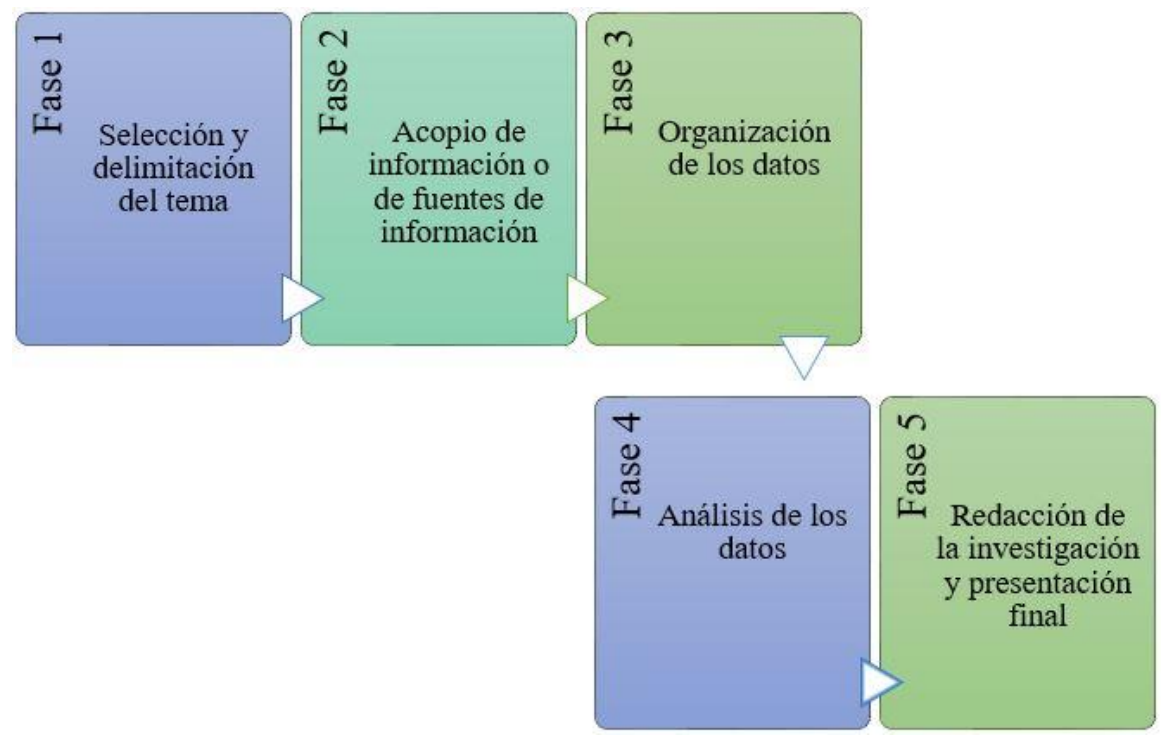

Fuente: Elaboración propia a partir de Espinoza y Rincón (2006) 
Revista Iberoamericana

de las Ciencias Sociales y

Humanísticas

\section{Método para el acopio de la información Área de estudio}

Para dar seguimiento a esta investigación se tomó como área de estudio el parque Nishi-Rokugō, ubicado en Nishirokugo, Ota-ku (Tokio), en el distrito de Ota, Japón (Japan Hoppers, 2017) (figura 2).

Figura 2. Ubicación del parque Nishi-Rokugō (Parque de los neumáticos)

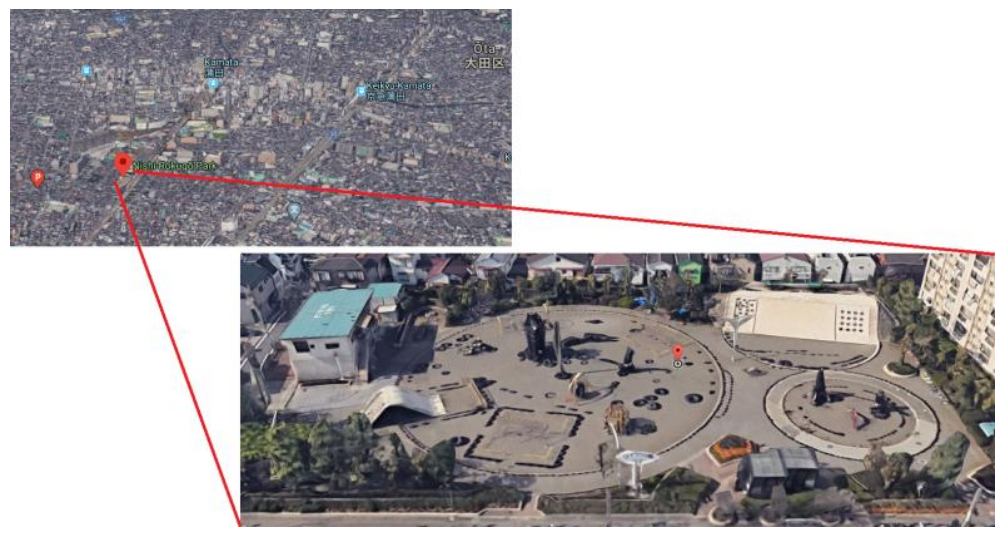

Fuente: Elaboración propia a partir de imágenes de Google Maps (2020)

En cuanto a las características físicas de dicho espacio, cabe mencionar que unos 40000 pies cuadrados $\left(3716.122 \mathrm{~m}^{2}\right)$ de tierra están designados a uno de los parques infantiles más extraños e innovadores del mundo (figura 3), fabricado casi exclusivamente con neumáticos. El parque está lleno de más de 3000 neumáticos de caucho reciclados de las cercanas plantas de fabricación de Kawasaki (Atlas Obscura, 2020).

Figura 3. Parque Nishi-Rokugō (Parque de los neumáticos)

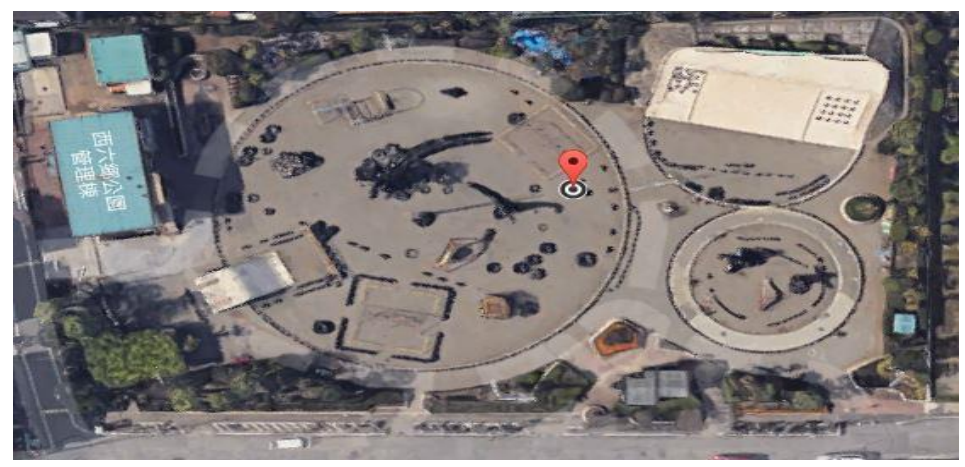

Fuente: Elaboración propia a partir de imágenes de Google Maps (2020) 
Revista Iberoamericana

de las Ciencias Sociales y

Humanísticas

ISSN: 2395 - 7972

\section{Resultados}

Con la dinámica expansiva de las ciudades y la urbanización de la vida, los parques empiezan a ser vistos como naturaleza urbana por sus funciones y valores ambientales (Vélez, 2009). En tal sentido, los materiales reciclados reducen al mínimo el empleo de componentes como el hierro y, sobre todo, las uniones con soldadura (García y Sáiz, 2014). Esto, lógicamente, puede traer beneficios sustanciales para la sociedad y el medio ambiente, pues brindan la oportunidad de crear no solo espacios útiles y funcionales, sino también conciencia en los ciudadanos.

Una visita al parque de neumáticos es una experiencia como ninguna otra en Tokio. En el parque hay cientos de neumáticos de todas las formas y tamaños usados de manera creativa. Algunos están esculpidos en robots o dragones, y hay túneles y montañas perfectas para escalar (Wiltshire y Huey, 2000) (figura 4).

Figura 4. Escultura del robot con neumáticos reciclados

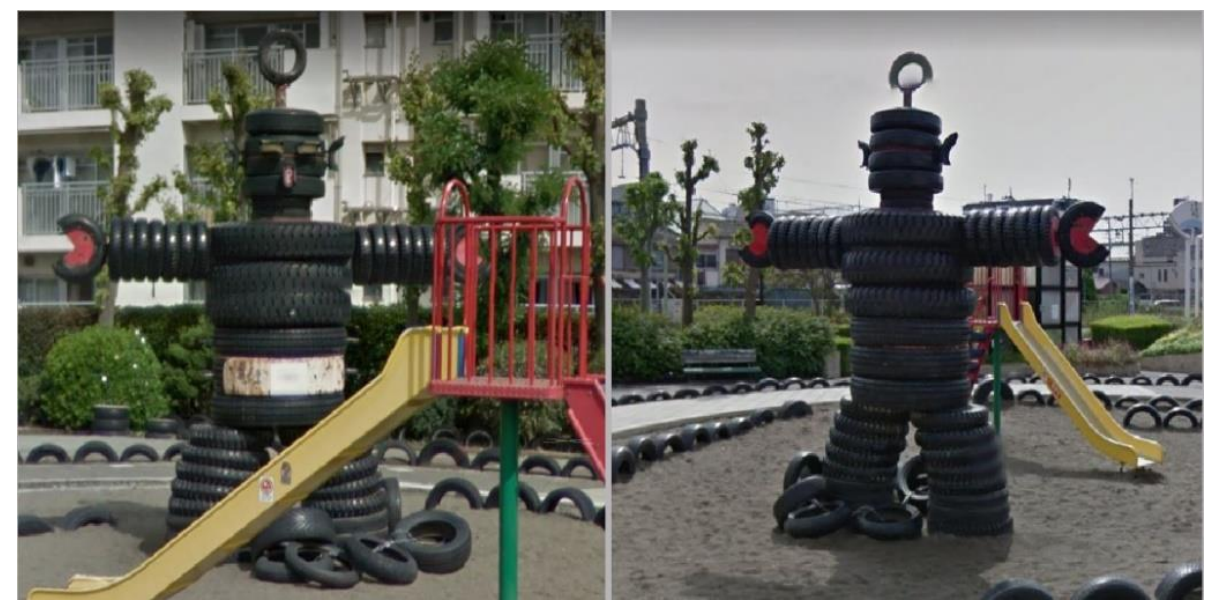

Fuente: Elaboración propia a partir de imágenes de Google Maps (2020)

Como se puede observar en la figura anterior, en los entornos urbanos japoneses resulta esencial el reciclaje, proceso que sirve para diseñar formas artísticas en espacios públicos que procuran un mejor bienestar social y ambiental para niños, jóvenes, adultos y adultos mayores. Este parque de neumáticos, en pocas palabras, es la representación perfecta de una atracción para todos que logra su cometido con el desarrollo de la imaginación (Matías, 2009).

Con este tipo de iniciativas queda en evidencia que es posible combinar lo natural con el reciclaje e incluso con la tecnología moderna, lo cual se enseña en la siguiente 


\section{Revista Iberoamericana de las Ciencias Sociales y Humanísticas}

escultura (figura 5), prototipo de nave espacial elaborada con neumáticos reciclados de las fabricas vecinales del distrito.

Figura 5. Nave espacial a base de neumáticos reciclados

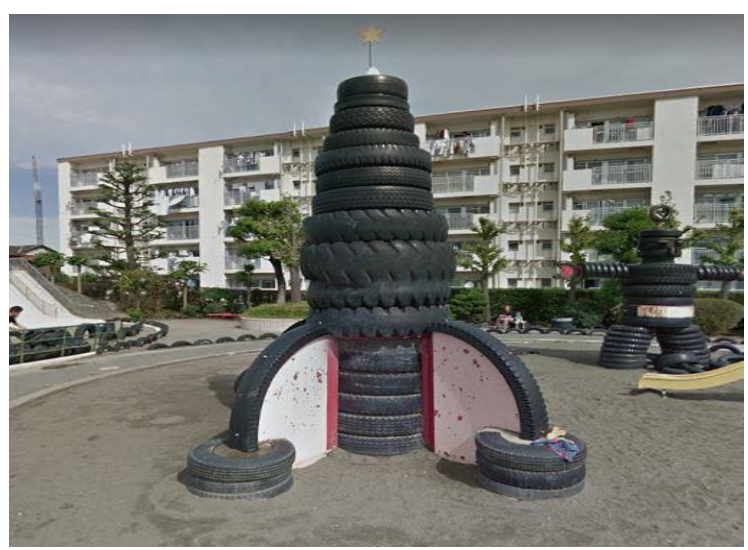

Fuente: Elaboración propia a partir de imágenes de Google Maps (2020)

Como ya se mencionó, Godzilla es otro personaje de la cultura nipona representado con los referidos materiales, el cual alcanza los cinco metros de altura y despierta el interés de los ciudadanos por el reciclaje (García y Sáiz, 2014) (figura 6).

Figura 6. Escultura del enigmático personaje conocido como Godzilla

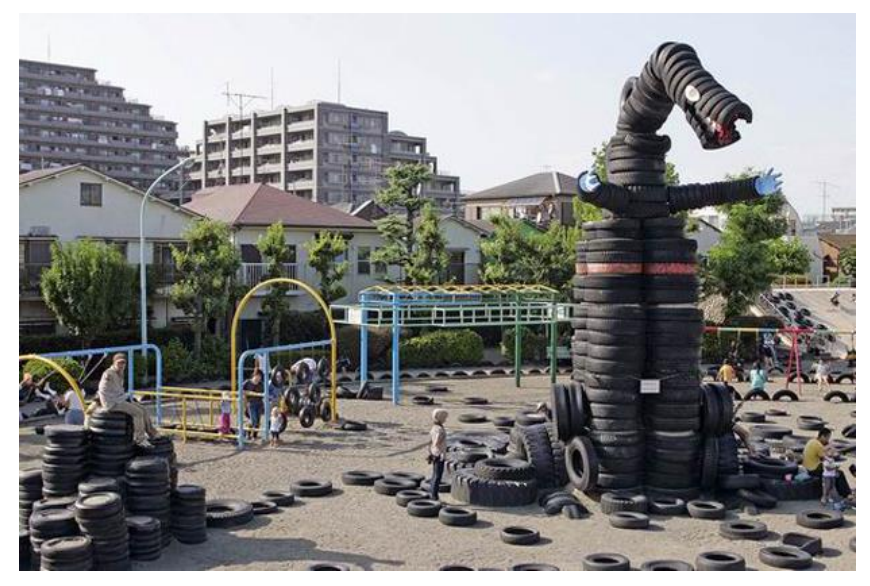

Fuente: Bellissima Kids (26 de junio de 2013)

En las figuras anteriores se puede apreciar que la realidad del paisaje urbano japonés ganó aceptación rápidamente, mientras que el contraste entre lo tradicional y lo contemporáneo se volvió la imagen más representativa de esa ciudad (Santini, 2015); es decir, la mezcla del paisaje urbano y la cultura del reciclaje consiguen este tipo de lugares para el esparcimiento de las familias locales (figura 7). 


\section{Revista Iberoamericana de las Ciencias Sociales y Humanísticas}

Figura 7. Familia en el parque Nishi-Rokugō, Tokio (Japón)

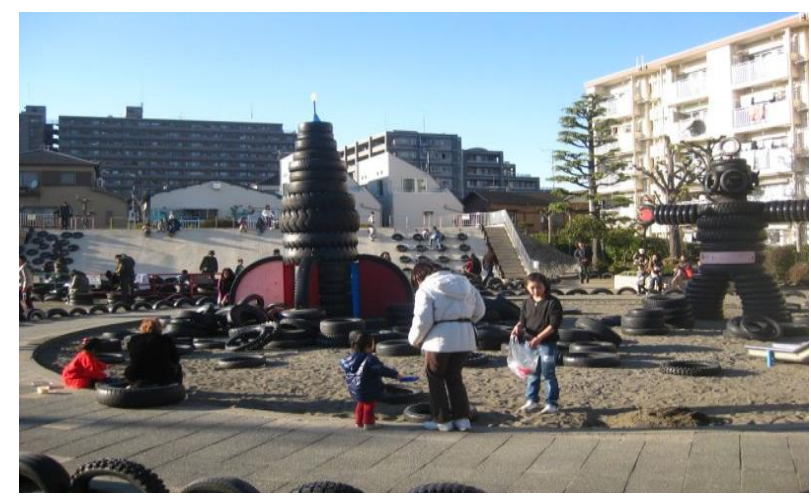

Fuente: Dohrenwend (2013)

Si bien el parque tiene instalaciones para los niños, como columpios, gimnasio en la selva, pilas de neumáticos para rebotar e incluso una gran pendiente de hormigón utilizada por los niños más aventureros, también existen otros espacios sombreados que son aprovechados por los ancianos para disfrutar del ambiente y admirar las 28 esculturas disponibles. De hecho, el parque está rodeado de hermosos macizos de flores que están bien mantenidos (Ponce, 2017) (figura 8).

Figura 8. Vegetación diversa dentro del parque

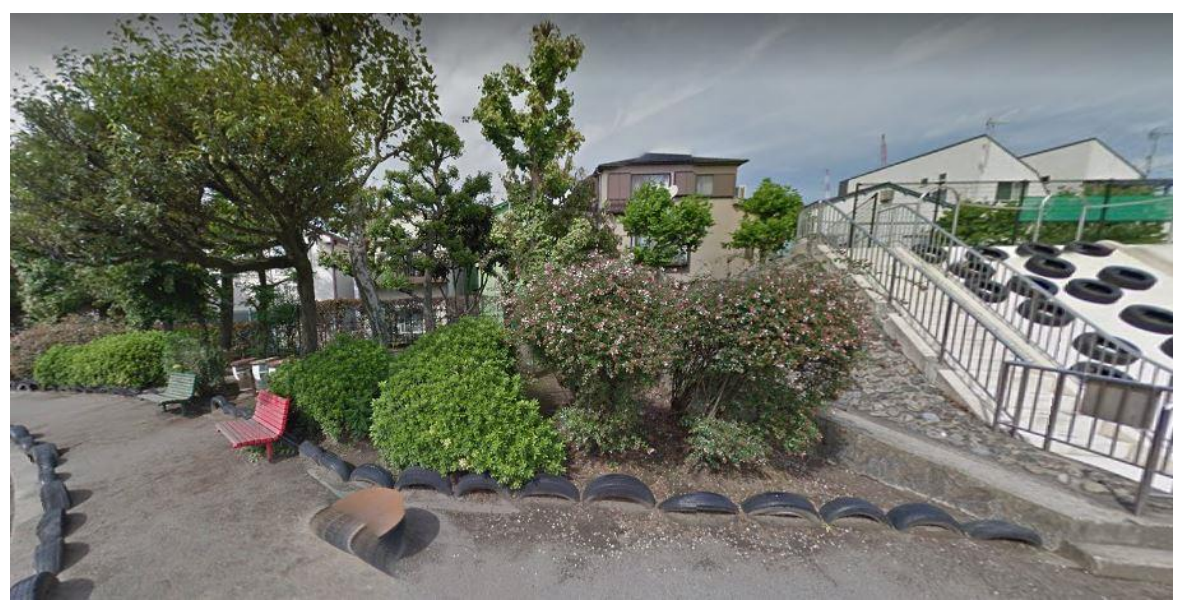

Fuente: Elaboración propia a partir de imágenes de Google Maps (2020)

De acuerdo con los criterios de sustentabilidad, la existencia de determinados atributos o características ecológicas, ambientales y sociales son principios que definen su estructura y funcionamiento y que se convierten en beneficios para el presente y futuro de la ciudad (Vélez, 2009). Así pues, Japón es el país que más ha progresado en estas rutas 
Revista Iberoamericana

de las Ciencias Sociales y

Humanísticas

ISSN: $2395-7972$

alternativas, cuyo interés reside en sus posibilidades de aplicación a nivel nacional, combinando las políticas medioambientales (Arandes et al., 2004).

\section{Discusión}

Las necesidades de contar con este tipo de espacios se relacionan con el bienestar social y ambiental de una ciudad que está en constante movimiento. En tal sentido, se pueden encontrar muchos más parques dentro de Japón, pero el Nishi-Rokugō es la excepción, pues enseña cómo los ciudadanos agregan un valor a su cotidianidad con este tipo de espacios. De hecho, en este parque se mezclan la cultura, la tradición y la innovación. Este tipo de parques, además, puede generar todo tipo de actividades sociales y ambientales que sirven para la recreación, relajación y convivencia familiar.

Se pone en manifiesto, por tanto, que el ingenio japonés se apoya en el reciclaje para abordar problemáticas dentro de sus entornos urbanos, lo cual permite avanzar hacia una cultura de preservación de lugares importantes para la vida diaria de los actuales habitantes, así como de las generaciones futuras, las cuales seguramente continuarán con este legado sustentable. Por lo tanto, conceptos como el honor, la belleza o el arte adquieren matices más profundos de los que podemos intuir (García, 2019).

\section{Conclusión}

Si la cultura y la reutilización de los residuos sólidos se tomaran de manera sensata, se podrían conseguir resultados ambientales y sociales efectivos. Para alcanzar tal objetivo, la práctica del reciclaje podría impulsarse con base en el modelo japonés, donde la educación, la cultura y la creatividad — sin dejar de lado el apoyo gubernamental— generan propuestas estables para un futuro sustentable en espacios de esparcimiento para la ciudadanía en general.

El parque Nishi-Rokugō, por tanto, constituye un gran referente para el resto de los países, pues se evidencia cómo la cultura de las personas es parte vital para impulsar cambios en las ciudades, donde se necesitan entornos para hacer una pequeña pausa en medio de una cotidianidad tan agitada. 


\section{Futuras líneas de Investigación}

Las siguientes son algunas de las líneas de investigación que se pueden impulsar basadas en la cultura del reciclaje y la sustentabilidad en diferentes ámbitos urbanos:

- Aplicar el estudio realizado en cuanto a la cultura del reciclaje dentro de las grandes, medianas y pequeñas ciudades.

- Realizar estudios comparativos siguiendo líneas sustentables y de reciclaje para la creación y generación de espacios urbanos.

- Preparar y evaluar programas sociales orientados al recicle para fomentar una educación ambiental.

- Iniciar investigación basada en modelos propuestos de parques a partir del reciclaje.

Este tipo de iniciativas propuestas deben ser desarrolladas por personas interesadas en conocer cómo están conformados este tipo de parques para ofrecer alternativas a problemas sociales y ambientales dentro de ciudades que se hallan en constante crecimiento. Esto, además, enseñará a las futuras generaciones el valor y el cuidado de los espacios urbanos, los cuales proporcionan un impacto positivo en las diferentes maneras de ver el cuidado ambiental.

\section{Referencias}

Alfonzo, I. (1994). Técnicas de investigación bibliográfica. Caracas: Contexto Ediciones.

Arandes, J. M., Bilbao, J. y López, D. (2004). Reciclado de residuos plásticos. Revista Iberoamericana de Polímeros, 5(1), 28-45.

Atlas Obscura (2020). Nishi-Rokugō Park Tokyo, Japan. Atlas Obscura. Retrieved from https://www.atlasobscura.com/places/nishi-rokugo

Becker, M. B. (2012). Parque urbano umbral de la ciudad y el territorio (tesis de grado). Pontificia Universidad Católica de Valparaíso: Chile.

Bellissima Kids (26 de junio de 2013). Nishi Rokugo Park, Tokyo. Retrieved from http://bellissimakids.com/nishi-rokugo-park-tokyo/

Dohrenwend, A. (2013). Nishi Rokugo Koen (Tire Park). Playscapes. Retrieved from http://www.play-scapes.com/correspondent_post/nishi-rokugo-koen-tire-park/

Espinoza, N. y Rincón, A. G. (2006). Instrucciones para la elaboración y presentación de monografías. La visión de la Facultad de Odontología de la Universidad de Los 
Revista Iberoamericana

de las Ciencias Sociales y Humanísticas

ISSN: 2395 - 7972

Andes. Acta Odontológica Venezolana, 44(3). Recuperado de http://ve.scielo.org/scielo.php?script=sci_arttext\&pid=S0001-63652006000300019

García, J. y Sáiz, B. (2014). Diseño y construcción de un parque infantil con elementos reutilizados en Kumbungu, Ghana (tesis de maestría). Universitat Politécnica de Valencia: España.

García, P. (2019). La mentalidad colectiva japonesa y el papel de la arquitectura (manuscrito inédito). Arquitectura Escuela Técnica Superior, Universidad de Sevilla.

Google Maps (2020). Mapa de Nishi-Rokugō Park. Recuperado de https://www.google.com.mx/maps/place/Nishi-

Rokug\%C5\%8D+Park/@35.5525726,139.7112733,251a,35y,358.65h,18.37t/data=! 3m1!1e3!4m8!1m2!2m1!1sNishiRokug\%C5\%8D+Park!3m4!1s0x0:0x1a6297e59a2 $70 \mathrm{c} 6 \mathrm{~b} ! 8 \mathrm{~m} 2 ! 3 \mathrm{~d} 35.5532477 ! 4 \mathrm{~d} 139.7116756$

Japan Hoppers (2017). Parque Nishi Rokugo (Parque de los neumáticos). Japan Hoppers. Recuperado de https://www.japanhoppers.com/es/kanto/tokyo/kanko/2841/

López, N. C. (2009). Propuesta de un programa para el manejo de los residuos sólidos en la plaza de mercado de Cerete-Cordoba (tesis maestría). Universidad Pontificia Javeriana: Bogotá.

Matías (2009). El parque de los neumáticos en Japón. Locuraviajes. Recuperado de https://locuraviajes.com/el-parque-de-los-neumaticos-en-japon/

Mejía, G. (2019). The use of parks and green areas of a city: social and environmental benefits. Asian Journal of Natural \& Applied Sciences, 8(1-4), 8-14.

Mesa, S. C. y Villa, M. A. (2016). La política ambiental japonesa y la movilización de industrias por la protección ambiental. Revista Digital Mundo Asia Pacífico [MAP], 5(8), 43-50. Doi: 10.17230/map.v5.i8.04

Miranda, C. E. (1997) Lo ambiental desde la perspectiva filosófica (tesis de maestría). CIIEMAD/IPN: México, D.F.

Mora, J. S. (2018). Análisis comparativo del marco regulatorio del servicio público de aseo entre Colombia y Japón (proyecto de grado). Universidad Distrital Francisco José de Caldas: Bogotá D.C.

Parques de México (2014). Parque de juego con neumáticos. Parques de México. Recuperado de http://www.parquesdemexico.org/consultora/parques-de-juego-conneumaticos/ 
Revista lberoamericana

de las Ciencias Sociales y Humanísticas

ISSN: 2395 - 7972

Ponce, J. C. (2017). Estudio y diseño del parque ecológico para el Cantón Coronel Marcelino Maridueña, año 2017 (tesis de licenciatura). Universidad de Guayaquil: Ecuador.

Restrepo, L. M. (s. f.). Investigación documental. Recuperado de http://aprendeenlinea.udea.edu.co/lms/moodle/file.php/658/Glosario_Invest_Docum ental_final_-_Lina_Rpo.pdf

Santini, T. (2015). Japón urbano. Revaloraciones y comprensión de la ciudad Nipona. Anales de Investigación en Arquitectura, 5, 93-111.

Tron, F. (2011). La gestión de residuos sólidos en Tokio, París, Madrid y México. Cuaderno de Investigación Urbanística, (75), 2-114.

Valderrama, M. F., Chavarro, L. E., Osorio, J. C. y Peña, C. C. (2018). Estudio dinámico del reciclaje de envases pet en el Valle del Cauca. Revista Lasallista de Investigación, 15(1), 67-74. Doi: 10.22507/rli.v15n1a6

Velázquez, Y. (2012). El reciclaje: una opción para minimizar la generación de residuos sólidos urbanos domiciliarios. DELOS Revista Desarrollo Local Sostenible, 5(15), $1-12$.

Vélez, L. A. (2009). Del parque urbano al parque sostenible. Bases conceptuales y analíticas para la evaluación de la sustentabilidad de parques urbanos. Revista de Geografía Norte Grande, 43, 31-49.

Wiltshire, D. and Huey, J. (2000). Japan for Kids: The Ultimate Guide for Parents and Their Children ( $2^{\text {nd }}$ ed.). Usa: Kodansha USA. 